\title{
Retraction Note to: Impact of PM2.5 environmental regulation based on big data for green technology development
}

\author{
Yijun Liu $^{1,2} \cdot$ Ziyang Fang $^{1} \cdot$ Fei Chen ${ }^{2}$
}

Published online: 14 December 2021

C) Saudi Society for Geosciences 2021

Retraction Note to: Arabian Journal of Geosciences (2021) 14: 649 https://doi.org/10.1007/s12517-021-06900-2

The Editor-in-Chief and the Publisher have retracted this article because the content of this article is nonsensical. The peer review process was not carried out in accordance with the Publisher's peer review policy. Author Fei Chen disagrees with this retraction. Author Yijun Liu has not responded to correspondence regarding this retraction. The Publisher has not been able to obtain a current email address for author Ziyang Fang.

The original article can be found online at https://doi.org/10.1007/ s12517-021-06900-2.

Fei Chen

18769955875@139.com

1 School of Economics and Management, Jiangxi University of Science and Technology, Ganzhou 341000, Jiangxi, China

2 College of Commerce, Jeonbuk University, Jeonju-si, Jeollabuk-do 54896, Republic of Korea 